\title{
Instantaneous activation energy of alkali activated materials
}

\author{
Shiju Joseph ${ }^{1}$, Siva Uppalapati ${ }^{1}$, Özlem Cizer ${ }^{1}$ \\ ${ }^{1}$ Department of Civil Engineering, KU Leuven, Belgium
}

Received: 8 February 2019 / Accepted: 05 March 2019 / Published online: 12 March 2019

(C) The Author(s) 2019. This article is published with open access and licensed under a Creative Commons Attribution 4.0 International License.

\begin{abstract}
Alkali activated materials (AAM) are generally cured at high temperatures to compensate for the low reaction rate. Higher temperature accelerates the reaction of AAM as in cement-based materials and this effect is generally predicted using Arrhenius equation based on the activation energy. While apparent activation energy is calculated from parallel isothermal calorimetry measurements at different temperatures, instantaneous activation energy is typically measured using a differential scanning calorimeter. Compared to the apparent activation energy, instantaneous activation energy has minimal effects on the microstructural changes due to the variation in temperature. In this work, the evolution of activation energy was determined by traditional methods and was compared with the instantaneous activation energy. It was found that while the activation energy changed with the progress of reaction, the instantaneous activation energy did not show any changes or remained the same. The instantaneous activation energy was also found to be higher compared to the apparent activation energy determined with traditional methods.
\end{abstract}

Keywords: Activation energy; Alkali activated materials; Calorimetry; Blast furnace slag; Fly ash

\section{Introduction}

Alkali activated materials (AAM) are often considered as an alternative to ordinary Portland cement, which is associated with significant amounts of $\mathrm{CO}_{2}$ emissions and responsible for $8 \%$ of the anthropogenic global $\mathrm{CO}_{2}$ emissions (Boden, Andres, \& Marland, 2016). These binders are derived mostly or entirely from industrial by-products, such as ground granulated blast furnace slag and coal combustion fly ash, with up to $70 \%$ less $\mathrm{CO}_{2}$ emissions compared to that of OPC (Duxson, Provis, Lukey, \& van Deventer, 2007). Strong alkalis such as sodium silicate $\left(\mathrm{Na}_{2} \mathrm{SiO}_{3}\right)$ and sodium hydroxide $(\mathrm{NaOH})$ are added for the purpose of enhancing their low reactivity. To boost their slow strength development, high temperatures are often used especially at high amounts of fly ash. Nevertheless, in reality different temperature regimes can be applied to these systems depending on the ambient conditions.

The sensitivity of a binder system to temperature can be explained using "apparent" activation energy concept derived from the Arrhenius equation (Eq. 1). The term "apparent" activation energy is coined for cementitious systems instead of activation energy to take into account several simultaneous reactions which take place in these complex systems using the Eq.1.

$$
k(T)=A \cdot \exp \left(\frac{-E a}{R \cdot T}\right)
$$

Where, $k$ is the temperature sensitive rate or rate constant, $A$ is constant of proportionality, Ea is the activation energy, $R$ is the universal gas constant, and $T$ is the absolute temperature. In cementitious systems, the Arrhenius equation is generally used in one of the simplified form as shown in Eq. 2 or Eq. 3. A more detailed review of apparent activation energy and the methods to determine it can be found elsewhere (Schindler, 2004) (Poole, Riding, Folliard, Juenger, \& Schindler, 2007).

$$
\begin{gathered}
\left(\frac{d \alpha}{d t}\right)_{\alpha=\alpha_{0}}^{T=T_{2}}=\left(\frac{d \alpha}{d t}\right)_{\alpha=\alpha_{0}}^{T=T_{1}} \cdot \exp \left\{-\frac{E a}{R} \cdot\left(\frac{1}{T_{2}}-\frac{1}{T_{1}}\right)\right\} \\
\tau\left(T_{2}\right)=\tau\left(T_{1}\right) \cdot \exp \left\{-\frac{E a}{R} \cdot\left(\frac{1}{T_{2}}-\frac{1}{T_{1}}\right)\right\}
\end{gathered}
$$

Where $\alpha$ is the degree of reaction, $T_{1}$ and $T_{2}$ are absolute temperatures, $\tau$ is the equivalent time according to the maturity concept, $\alpha$ is the degree of reaction. If we assume, $\alpha=\frac{Q(t)}{Q_{\infty}}$, where $Q$ is the cumulative heat released measured from isothermal calorimeter, Eq. 2 could be rewritten as follows:

$$
k_{1}=k_{2} \cdot \exp \left\{-\frac{E a}{R} \cdot\left(\frac{1}{T_{2}}-\frac{1}{T_{1}}\right)\right\}
$$

Where $k_{1}$ and $k_{2}$ are the rate of heat release measured from isothermal calorimeter at similar $\mathrm{Q}(\mathrm{t})$.

Thomas (Thomas, 2012) noted that while the apparent activation energy, which was calculated using Eq. 4, varied for Portland cement and tricalcium silicate $\left(C_{3} S\right)$, the

* Corresponding author: Shiju Joseph, E-mail: shiju.joseph@kuleuven.be 
instantaneous activation energy measured by changing the temperature during measurements within the calorimeter was constant. He concluded that this difference could be due to the microstructural changes taking place in cementitious systems.

In this work, the evolution of apparent activation energy for alkali activated slag-fly ash binder is investigated at different isothermal temperatures using Eq. 3 and Eq. 4. It is compared with the instantaneous activation energy measured using the technique developed in a previous study for $C_{3} S$ (Joseph, Bishnoi, van Balen, \& Cizer, 2018).

\section{Materials and methods}

Ground Granulated Blast Furnace Slag (GGBFS) and Class F fly-ash (FA) were used as a primary material in this study. The oxide compositions of these materials determined using XRF is given in Table 1. The alkali-activated GGBFS/FA blends were produced at $80: 20$ volume $\%$ of GGBFS/FA ratio (equivalent to $83: 17$ mass \%). Sodium silicate solution $\left(\mathrm{Na}_{2} \mathrm{O}-\right.$ 8.3\%, $\left.\mathrm{SiO}_{2}-27.5 \%, \mathrm{H}_{2} \mathrm{O}-64.2 \%\right)$ and sodium hydroxide pellets (99\% purity) were used as alkaline activators. The alkaline solutions were prepared by dissolving the sodium hydroxide in distilled water at least $24 \mathrm{~h}$ before use. The prepared sodium hydroxide (8M) was mixed with commercially available sodium silicate (39\%-40\% silicates in water; ABCR Gmbh \& Co. KG, Karlsruhe, Germany) in order to achieve sodium metasilicate with a required alkali modulus of 1.25 . Additional amount of water was added to achieve a water-tobinder ratio of 0.5 .

Table 1. Oxide composition of slag and fly ash

\begin{tabular}{|l|l|l|l|l|l|l|l|l|}
\hline $\begin{array}{l}\text { Mate } \\
\text { rials }\end{array}$ & $\mathrm{SiO}_{2}$ & $\mathrm{Al}_{2} \mathrm{O}_{3}$ & $\mathrm{Fe}_{2} \mathrm{O}_{3}$ & $\mathrm{CaO}$ & $\mathrm{MgO}$ & $\mathrm{SO}_{3}$ & $\mathrm{~K}_{2} \mathrm{O}$ & $\mathrm{Na}_{2} \mathrm{O}$ \\
\hline Slag & 36.2 & 12.4 & 0.6 & 39.8 & 7.3 & - & 0.5 & - \\
\hline $\begin{array}{l}\text { Fly } \\
\text { ash }\end{array}$ & 57.4 & 26.1 & 6.3 & 2.4 & 1.5 & 0.8 & 2.9 & 0.5 \\
\hline
\end{tabular}

TAM Air 8-channel isothermal microcalorimeter was used to measure the heat release at different temperatures. To determine the apparent activation energy, isothermal calorimetry measurements at three different temperatures were conducted $\left(20,30\right.$ and $\left.40^{\circ} \mathrm{C}\right)$. For the instantaneous activation energy, samples were prepared in ampules used for the calorimeter and were stored at a controlled temperature of $20^{\circ} \mathrm{C}$ for different curing ages. After attaining the required curing period, they were transferred to the calorimeter at $30^{\circ} \mathrm{C}$. To reduce the intensity of error derived from transfer of sample from a different temperature, reference samples of equivalent thermal mass, which were also stored at $20{ }^{\circ} \mathrm{C}$, were used. Nevertheless, data of the initial 30 minutes were discarded as they are still highly prone to error.

\section{Results and discussion}

Fig. 1 shows the effect of different temperature $(20,30$ and $40{ }^{\circ} \mathrm{C}$ ) on the heat release. As expected, with an increase in the temperature, the main peak of reaction occurs sooner and at a higher intensity.

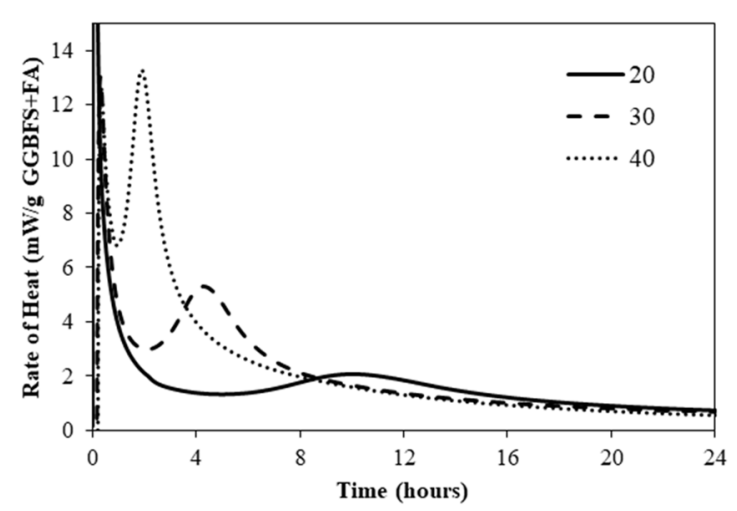

Figure 1. Effect of temperature $\left(20,30\right.$ and $\left.40{ }^{\circ} \mathrm{C}\right)$ on the rate of heat released using isothermal calorimeter.

Fig. 2 plots the rate of heat release with respect to the cumulative heat measured with the isothermal calorimeter. The rate of heat release is always higher at a similar cumulative heat release with increasing temperature. This is contrary to what is observed for tricalcium silicate, which varies after a certain degree of hydration (Joseph, Bishnoi, van Balen, \& Cizer, 2018).

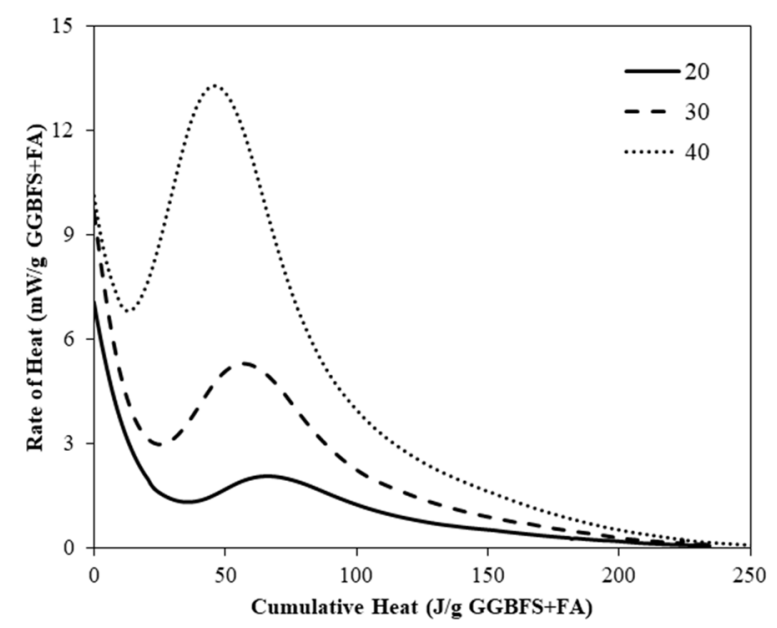

Figure 2. Effect of temperature $\left(20,30\right.$ and $\left.40^{\circ} \mathrm{C}\right)$ on the rate of heat released with respect to the cumulative heat released.

Fig. 3 (top) shows the evolution of apparent activation energy calculated using Eq. 2 while Fig. 3 (bottom) shows the activation energy calculated based on the maturity principle (Eq. 3). A variation of the activation energy is observed with the progress of reaction. Results from Fig. 3 (top) are similar to the results of $\mathrm{C}_{3} \mathrm{~S}$ and OPC (Thomas, 2012). This needs to be further investigated because a change in activation energy could also indicate a change in the mechanism controlling the reaction (Scrivener, Juilland, \& Monteriro, 2015). The average activation energies calculated using Eq. 2 and Eq. 3 are $53.1 \pm 16.5$ and $48.2 \pm 5.9 \mathrm{~kJ} / \mathrm{mol}$ respectively. These values are close to the activation energy determined for GGBFS earlier (Sun \& Vollpracht, 2018) (Fernandez-Jimenez, Puertas, \& Arteaga, 1998). 

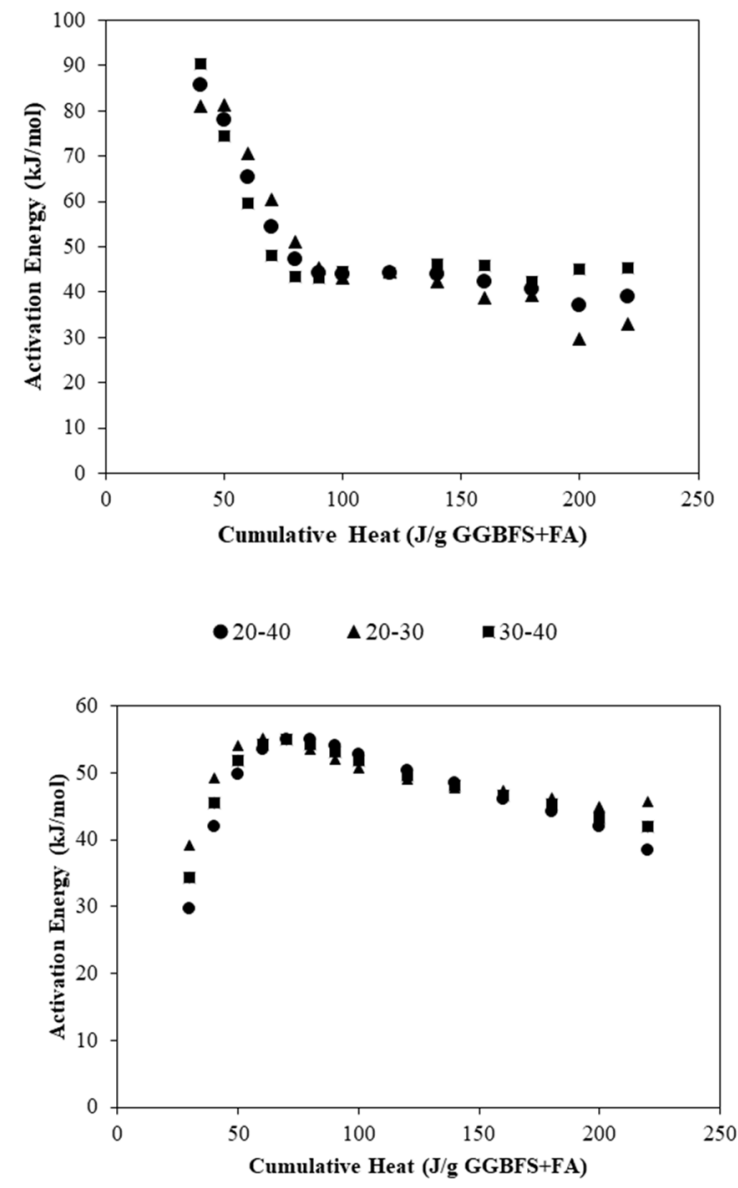

Figure 3. Evolution of apparent activation energy determined by Eq. 2 (top) and Eq. 3 (bottom).

Fig. 4 shows the instanteneous apparent activation energy. It is clearly seen that there is no significant deviation or change in the activation energy unlike Fig. 3. This implies that the reaction mechanism is goverend by chemically controlled reactions (Lasaga, 1998). The average activation energy is $75.2 \pm 6.7 \mathrm{~kJ} / \mathrm{mol}$ which is higher than what is measured from Eqs. 2 and 3. A recent study has also reported variation in the activation energy based on Eq. 2 for a fly ash based system (Nath \& Kumar, 2019). Since all the activation energies reported for alkali activated materials used one of these equations, future studies should look more critically on the method for determining the activation energy.

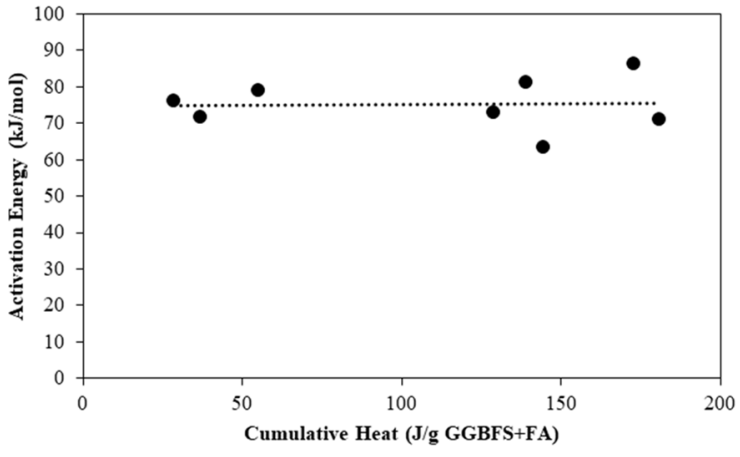

Figure 4. Evolution of the instanteneous apparent activation energy.

\section{Conclusions}

In this work, the activation energy of alkali activated slag-fly ash blend activated using $\mathrm{NaOH}$ and $\mathrm{Na}_{2} \mathrm{SiO}_{3}$ activaters was determined. The evolution of activation energy determined from parallel measurements at different temperatures was compared with the instantenious activation energy. It was found that while the traditional approach for finding activation energy changed over the course of the reaction, the instantenious activation energy did not show any changes. This implies that the reaction mechanism is goverend by chemically controlled reactions.

\section{References}

[1] T. Boden, B. Andres, G. Marland, Global CO2 emission from fossil-fuel burning, cement manufacture, and gas flaring, Oak Ridge National Laboratory (2016), Oak Ridge.

[2] P. Duxson, J. L. Provis, G. C. Lukey, J. S. J. van Deventer, The Role of Inorganic polymer Technology in the Development of Green Concrete, Cem Concr Res (2007) 37: 1590-1597. https://doi.org/10.1016/j.cemconres.2007.08.018

[3] A. K. Schindler, Effect of temperature on hydration of cementitious materials, ACI Mater J (2004)101:72-81.

[4] J. L. Poole, K. A. Riding, K. J. Folliard, M. Juenger, A. K. Schindler Methods for calculating activation energy of Portland cement, $\mathrm{ACl}$ Mater J (2007) 104:303-311. https://doi.org/10.14359/18499

[5] J. J. Thomas, The Instantaneous Apparent Activation Energy of Cement Hydration Measured Using a Novel Calorimetry-Based Method, J Am Ceram Soc (2012) 95: 3291-3296. https://doi.org/10.1111/j.1551-2916.2012.05396.x

[6] S. Joseph, S. Bishnoi, K. van Balen, O. Cizer, Effect of the densification of C-S-H on hydration kinetics of tricalcium silicate, J Am Ceram Soc (2018) 101: 2438-2449. https://doi.org/10.1111/jace.15390

[7] K. L. Scrivener, P. Juilland, P. J. Monteriro, Advances in understanding hydration of Portland cement, Cem Concr Res (2015) 78:38-56. https://doi.org/10.1016/i.cemconres.2015.05.025

[8] Z. Sun, A. Vollpracht, Isothermal calorimetry and in-situ XRD study of the $\mathrm{NaOH}$ activated fly ash, metakaolin and slag, Cem Concr Res (2018) 103:110-112. https://doi.org/10.1016/j.cemconres.2017.10.004

[9] A. Fernandez-Jimenez, F. Puertas, A. Arteaga, Determination of kinetic equations of alkaline activation of blast furnace slag by means of calorimetric data, J Therm Anal Calorim (1998) 52: 945-955. https://doi.org/10.1023/A:1010172204297

[10] A. C. Lasaga, Kinetic theory in the Earth Sciences ed. P.s.i. Geochemistry, Princeton University Press (1998).

[11] S. Nath, S. Kumar, Role of alkali concentration on reaction kinetics of fly ash geopolymerization, J Non-Cryst Solids (2019) 505:241-251. https://doi.org/10.1016/i.jnoncrysol.2018.11.007 